\title{
Burning Rate of Upholstered Chairs in the Center, alongside a Wall and in the Corner of a Compartment
}

\section{T. MIZUNO and K. KAWAGOE}

Center for Fire Science and Technology

Science University of Tokyo

2641, Yamasaki, Noda-shi

Chiba-ken, 278, Japan

\section{ABSTRACT}

This paper describes three series of fire tests of an upholstered chair for the investigation of their burning behavior and for the comparison of results between the three series, which were (1) C-series in which the test specimen was located at the center of a room, (2) W-series in which it was located alongside a wall, and (3) K-series in which it was located in the corner of walls. Measurements were made of the following items: mass burning rate, radiative heat transfer to the surroundings, heat transfer to the wall, optical smoke density, etc. In comparing the three series, no obvious difference between mass burning rates could be seen. This tendency were verified by the burning of wood cribs and urethane foams. In this paper only the comparison of mass burning rate is described.

keywords: burning rate, upholstered chair, full-scale burning test, burning position

\section{INTRODUCTION}

A study of the burning behavior of furniture in preflashover period was presented by Mizuno and Kawagoe in Ref.[1], in which the test item was located at the center of a test room. An engineering model of burning rate for upholstered chairs was proposed, too. Usually, furniture is placed not only in the center of a room but also alongside a wall or in the corner of the room. Saito[2] pointed out from the result of kerosene pool fire that the wall had the effects on the burning item within the distance of the wall two times burning source diameter. Walls and corners may have little effect unless the flames touch to the walls: In Sajto's result, when kerosene pan was placed close to the walls a flame touched to the walls, and a mass burning rate was larger than free burning. In the case of upholstered chairs, the chair can be roughly divided two parts of the seat cushion and the seat back. The seat cushion would not be placed close to a wall but the seat back can. Therefore, the presence of the wall would influence the burning rate, to say the least of it, of the seat back. However, it is not clear what differences of burning behavior, specialily, burning rate, would be found due to the position of furniture in a room, because there have been a little studies to investigate the burning behavior of furniture located alongside a wall or in the corner. 
In our earlier study[1], fire tests of wood cribs and chairs were conducted at the center of a room and the burning rate, smoke generation and radiant heat flux from flame were reported. Also it was pointed out that the mass burning rate is one of the key factors which describe the burning behavior. Then an engineering model for the mass burning rate was proposed for furniture on the basis of the results of wood crib tests.

Fig. 1 shows the mass burning rate curve of a wood crib in Ref.[1]. It reveals that a peak value appears at a few minutes after ignition, and it gradually decreases after the peak. It can be assumed that the burning rate after the peak is proportional to the residual weight. Rockett, also, points out in Ref. [3] that the burning rate of urethane foam after the peak is proportional to the residual weight using the test results by Babrauskas[4]. The assumption is expressed by the following equation:

$\dot{\mathrm{m}}=-\mathrm{dm} / \mathrm{d} t=A m$

where $\dot{m}$ is the mass burning rate,

$m$ is the residual weight, and

A is the burning coefficient.

Then, integration of equation (1) gives
$m=C \cdot \exp (-A t)$

where $C$ is the constant of integration. Let Tp denote the time to reach the peak mass burning rate and $r$ denote the rate of residual weight to the initial weight, mo, at the peak, then equation (2) becomes
$m=r \cdot m o \cdot \exp (-A(t-T p))$
$R W=m / m o=r \cdot \exp (-A(t-T p))$
Therefore equation (1) becomes
$\dot{m}=A \cdot r \cdot m o \cdot \exp (-A(t-T p))$
$(t>T p)$

Equations (3) and (5) include four characteristic burning parameters of $r, A$, Tp and mo. Equation (4) can be rewritten to; $\ln (R W)=-A t+\ln (r)+A \cdot T p$

By plotting a graph of RW vs. time, $t$, on a semi-log graph, the line of RW becomes a straight Tine and its slope is equivalent to

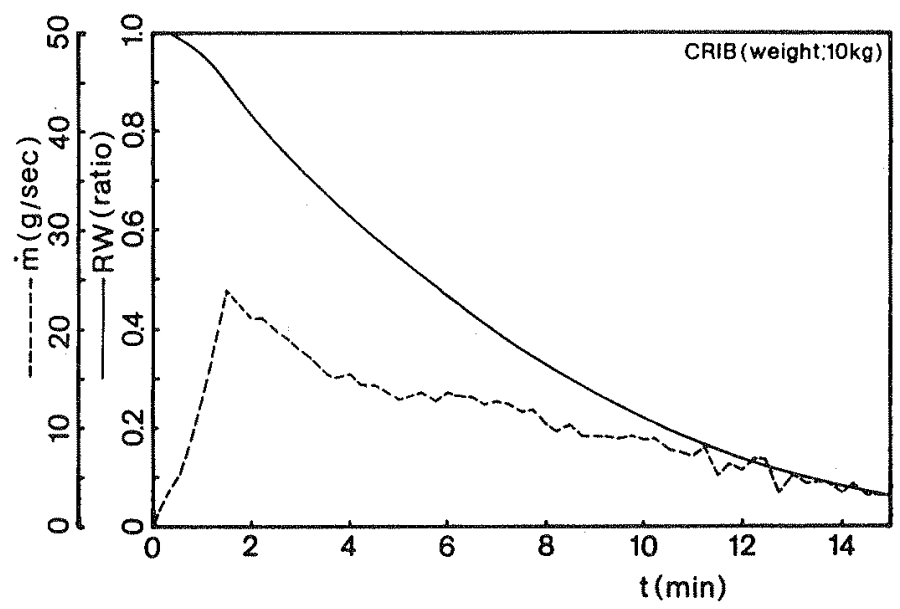

Fig.l Burning Rate and Residual Weight Ratio of Wood Crib 
the value of $A$ which indicates the intensity to burn.

In the case of chairs, by defining the modified initial weight, mo*, as the difference between the initial and final chair weight, and the modified residual weight, $m^{*}$, as the difference between the residual weight and the final chair weight, and adopting the modified residual weight ratio, $R W^{*}$, instead of RW, it may be possible to apply the model described before for upholstered chairs.

\section{EXPERIMENT AND RESULTS}

Three series of burning tests of upholstered chairs, wood cribs and urethane foams were conducted in a test room which has a volume of about $175 \mathrm{~m}^{3}$. floor dimensions of approximately $6 \mathrm{~m}$ by $6 \mathrm{~m}$, a height of $4.85 \mathrm{~m}$, and one doorway opening of $0.9 \mathrm{~m}$ width by $2.0 \mathrm{~m}$ height. The three series were (1) C-series: the test specimen was located at the center of a room, (2) W-series: alongside a wal1, and (3) K-series: in the corner of walls. The wal1 or corner erected in the test room was made of ALC ( Autoclaved Lightweight Concrete) boards of $120 \mathrm{~mm}$ thickness. The ceiling height of the test room was higher than a typical residential room, but this would not give any effect on the burning rate $[6][7]$.

The ignition sources for the chairs and the wood cribs consisted of the two chips of insulating fiber-board $(2 \times 20 \times 1 \mathrm{~cm})$ soaked with about $100 \mathrm{cc}$ of methanol which were placed on the seat of the chairs or under the crib, and for the urethane foams the ignition source was a Methenamine pill placed on the surface center of the foam. The test item was placed on a load-platform and their mass loss was measured with a set of load-cells at 15 second intervals. In the case of upholstered chairs, since foams and fabric generally burn first and the wood frame very slow, these tests were stopped when the remaining foam and fabric became very small.

\section{C-13 [330sec]}

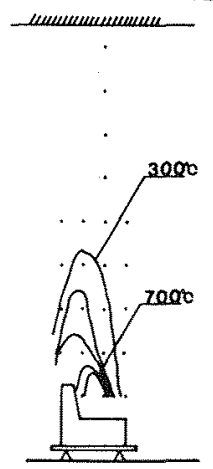

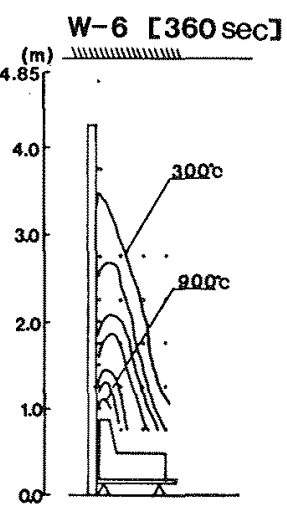

Fig.2 Typical Temperature Contour Map of Burning Chairs $\left(100^{\circ} \mathrm{C}\right.$ of interval of lines)

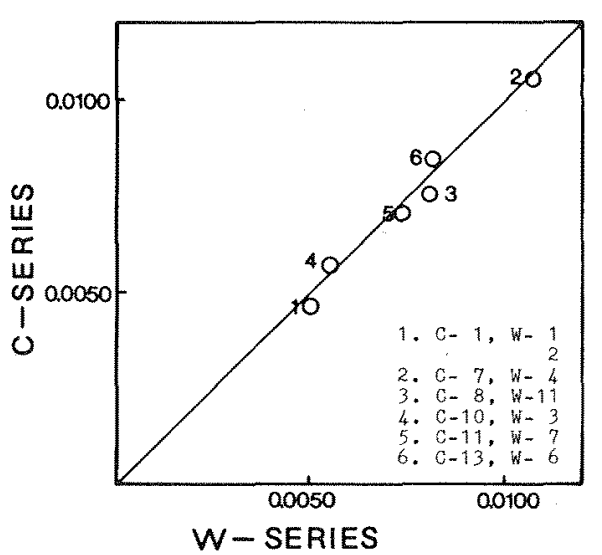

Fig. 3 Comparison of Parameter $A$ Between $C$ and $W$ series 


\subsection{Fire Tests of Chairs: Part 1. C-series and W-series}

Upholstered chairs of 46 in total [5] were burned at two positions in the room, and the following items were measured; flame height, mass burning rate, air temperature over the chair, room temperature, smoke density, etc. The most of chairs tested were used items including many kinds and shapes. In this study picking out the results of six sets of the same chairs on materials and chair shape, the comparison of mass burning rate between $\mathrm{C}$-series and $\mathrm{W}$-series is made.

Fig. 2 shows the typical temperature contour map of the same type of chairs, $C-13$ and $W-6$, at the time of the peak of burning. The mass burning rates of these chairs at the peak were the same value of about $25 \mathrm{~g} / \mathrm{sec}$. In the case of wall side test. $W-6$, it reveals high temperature near the wall surface comparing $300^{\circ} \mathrm{C}$ 7 ines shows that the flame in the case of wall side test leans against to the wall. However, Fig. 3 shows that there is no obvious difference in the parameter $A$ in equation (3) and (5). It was found that, when the upholstered chairs burn individually in the pre-flashover period, the burning rate may be assumed to be the same value whether the position of burning item is in the center of a room or alongside a wall. But, based on these results alone, it was difficult to affirm that.

\subsection{Fire Tests of Chairs: Part 2, C, W and K-series}

To explore further the former experimental results, two sets of 3 upholstered chairs of the same materials and the same shape were purchased and burned each in the center of the test room, along the side of a wall erected in the test room, and in a corner erected in the test room. The test specimens were commercial goods and very cheap ones, so they were consisted simply of only urethane foam and a cover fabric supported by a wood frame. The chairs of type $A, C C-1, W C-1$ and $K C-7$, were about $8.9 \mathrm{~kg}$ in weight. The chairs of type $B, C C-3, W C-2$ and $K C-$ 9 , were about $7.7 \mathrm{~kg}$. Materials and shapes of type $A$ and type $B$ chairs were almost the same kind of ones. $\mathrm{CC}-1$ and $\mathrm{CC}-3$ were tested in the center of the room, WC-1 and WC-2 along side the wa 11 , and $K C-7$ and $K C-9$ in the corner.

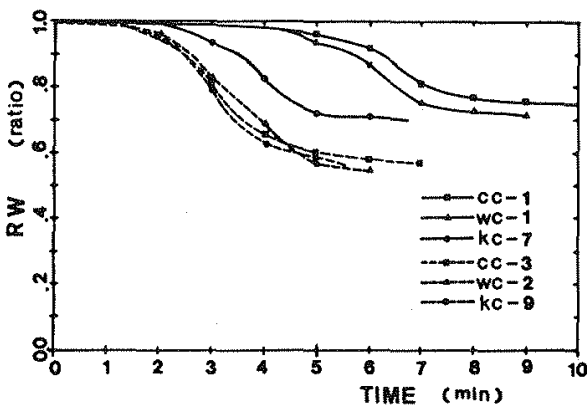

Fig. 4 Residual Weight Ratios of Upholstered Chairs

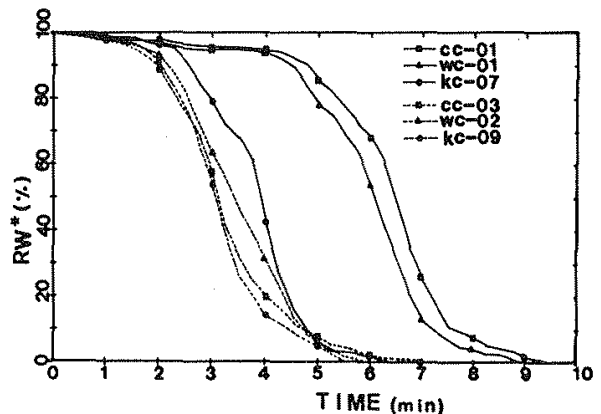

Fig. 5 Modified Residual Weight Ratios of Upholstered Chairs 
Fig. 4 shows the residual weight ratios of the burning chairs. These upholstered chairs burned very fast, much as the urethane foams because they were simple ones. The upholstered chairs described in section 2.1 burned more slowly than in this section because they consisted not only of a filling foam and a fabric cover but also an interlining, a suspension and/or a cotton batting, which slowed the burning rate of the chair.

The residual weight ratios of the chairs, when the tests were stopped, were almost the same value for each type. In the case of type A the ratios were about $70 \%$ and in the case of type $B$ they were about $60 \%$. The residual weights were nearly equal to the weights of frames; the upholstered chairs leave substantial residual mass due to unburnt parts such as the wood frame after the active burning period. Fig. 5 shows the modified residual weight ratios of the burning chairs. In the case of Fig.4, the times when the curves begin to drop are somewhat scattered, but the slopes of downward curves are roughly the same. Fig. 5 clearly shows this point.

The burning rate ratios of the chairs are shown in Fig.6. The plotting curves of the burning rate of chairs which burn sudden1y, as shown in Fig.6, indicate an evident peak. Comparing Fig. 5 and $\mathrm{Fig.6}$ shows that residual weight ratios at the peak are about $40 \%$. This tends to be a smaller value than found in section 2.1. It was observed that the flame of the seat back touched to the walls in the case of the corner tests, and in the case of type A chairs the peak value of the burning rate of $\mathrm{KC}-7$ is larger than in the other chairs. So, in the corner test there might be a bit effect of the wal1. However, the overall burning rate ratios within the three burning locations show no obvious differences. Thus, when the upholstered chairs burn individually
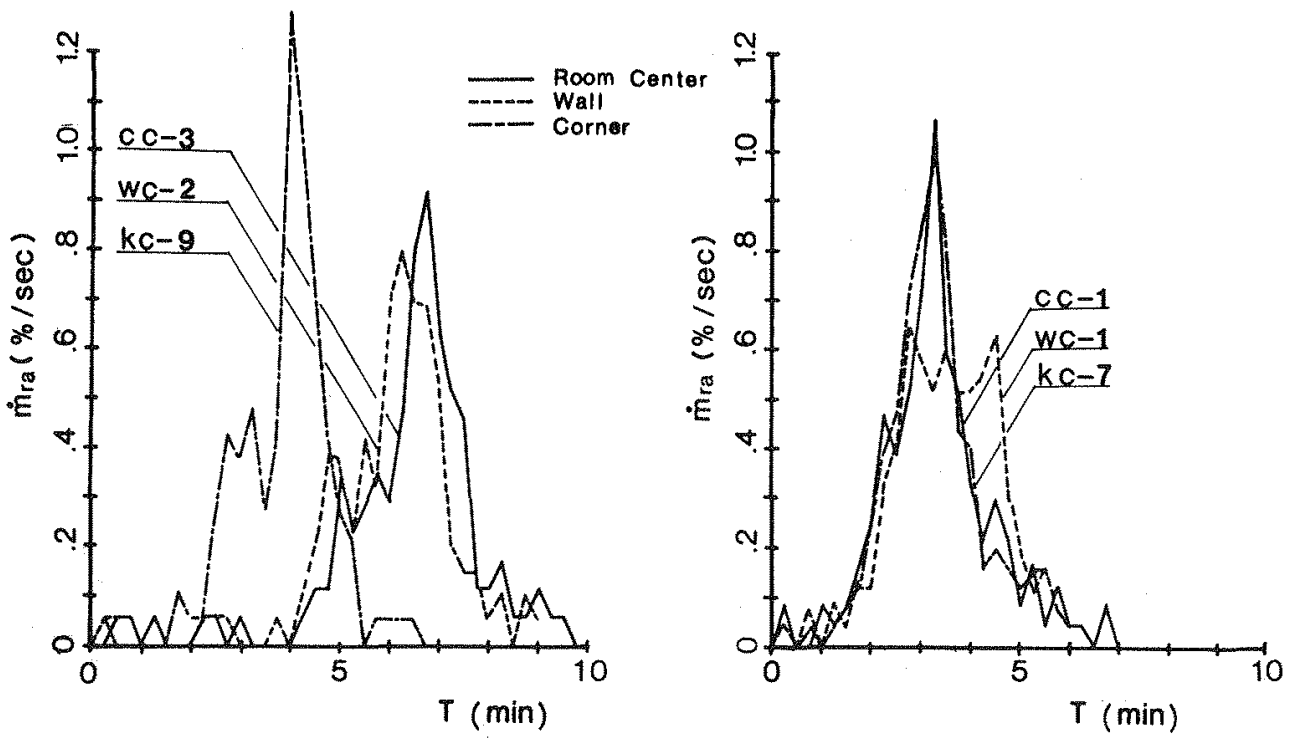

Fig.6 Burning Rate Ratios of Upholstered Chairs 


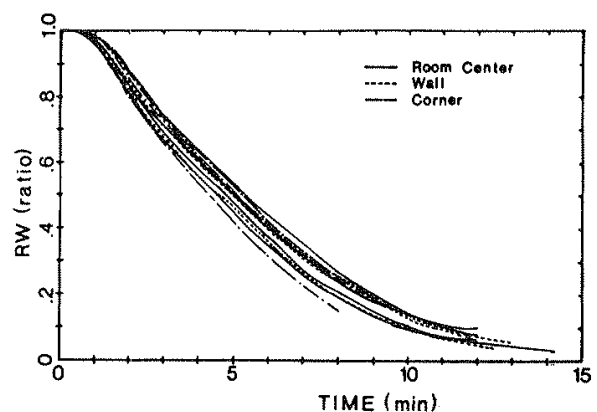

Fig. 7 Residual Weight Ratios of Wood Cribs

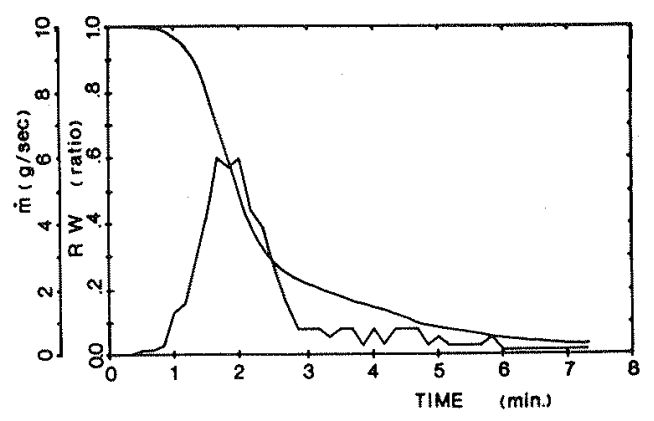

Fig.8 Typical Residual Weight Ratio and Burning Rate of Urethane Foam

the burning rate may be assumed, from an engineering point of view, to be the same value whether the position of burning item is at the center of a room, along the side of a wall, or in the corner of a room.

\section{3 Verification Tests by Wood Cribs and Urethane Foams}

In the second step, the burning tests using wood cribs and urethane foams were carried out to verify the results obtained from the burning of upholstered chairs.

The test setup for the wood cribs was the same as for the upholstered chairs. The wood cribs consisted of sticks of Japanese cedar, $4.5 \mathrm{~cm}$ by $3.5 \mathrm{~cm}$ with a length of $45 \mathrm{~cm}$. The number of sticks per layer was 4 and the number of layers 10; total weight of a wood crib was about $9 \mathrm{~kg}$.

Wood cribs burn very smoothly. Fig. 1 reveals a peak value at a few minutes after ignition, followed by a gradually decreases after reaching the peak. The time to reach the peak mass burning rate was about 120 seconds after ignition. In the corner tests it was observed that a flame touched to walls, and in the wall side tests it was not obvious. Thus, there might be a little effect of walls on the burning rate in the corner test.

Fig.7 shows the residual weight ratios of the wood cribs. The curves in Fig. 7 are closely coincident, and they indicate no obvious differences between the three burning positions. It could be concluded that walls have little effect on the burning rate.

Burning tests of urethane foams were, also, carried out with the same setup as for the upholstered chair tests. The urethane foam slabs had dimensions of $52 \mathrm{~cm}$ by $53 \mathrm{~cm}$, thickness of $6 \mathrm{~cm}$, and weight of approximately $250 \mathrm{~g}$. The density of the urethane foam was about $0.015 \mathrm{~g} / \mathrm{cm}^{3}$. Two types of tests, single slab tests and double slab tests, were conducted. In the double slab tests, slabs were piled up, so the burning area was the same within the two types of tests.

Fig. 8 shows the typical residual weight ratio and mass burning rate of the urethane foam in the corner of the test room. The curves of the burning rate as shown in Fig. 8 indicate a shape like a mountain, similar to that of the upholstered chairs. 


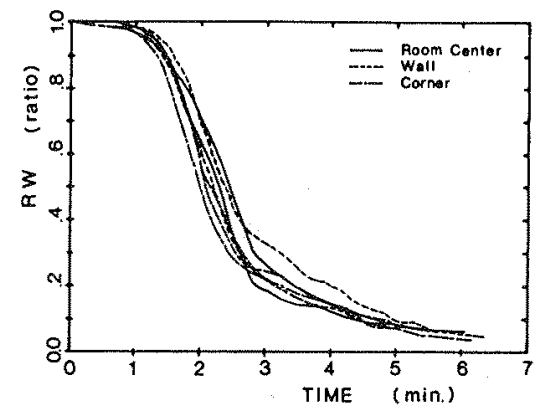

Fig. 9 Residual Weight Ratio of Urethane Foams (one slab)

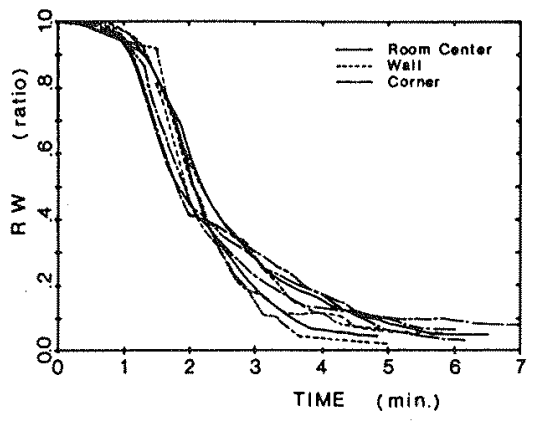

Fig. 10 Residual Weight Ratio of Urethane Foams (two slab)

In the corner tests it was observed, as same as in wood cribs tests, that a flame touched to walls, and in the wall side tests it was not obvious. Fig. 9 and Fig. 10 show the residual weight ratios of urethane foam. The curves of the residual weight ratio are closely coincident but in the case of double slab the slope of the curves of the corner tests may be a few greater than the others. However, in the roughly speaking, the curves of the residual weight ratio in Fig. 9 and Fig. 10 indicate no obvious difference between the three burning positions. Therefore, it could be also concluded that walls have little effect on the burning rate.

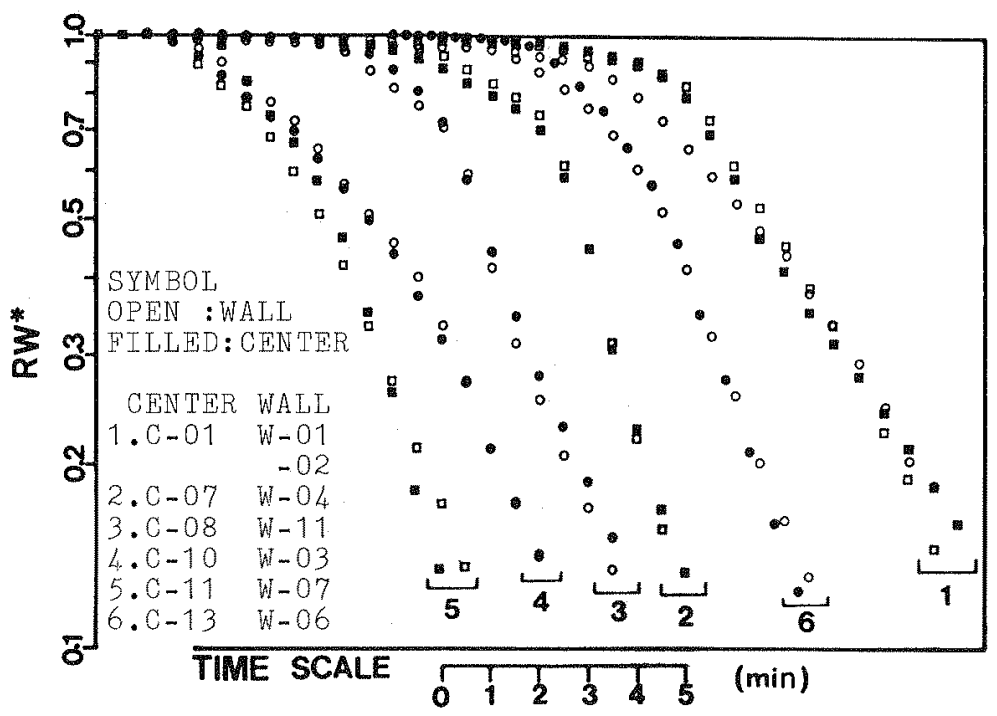

Fig. 11 Comparison of Modified Residual Weight Ratio 


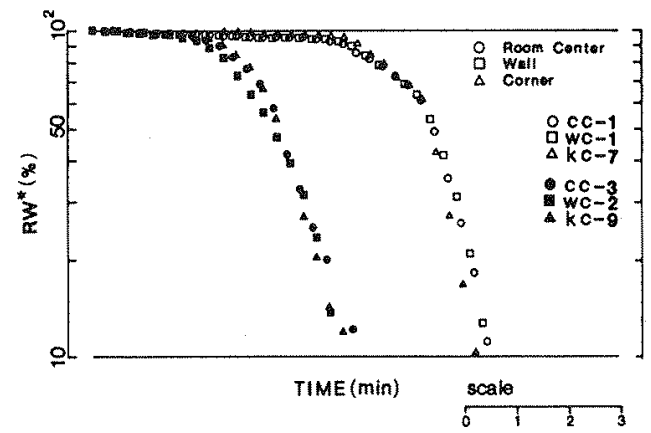

Fig. 12 Modified Residual Weight Ratios of Chairs in Semi-Tog

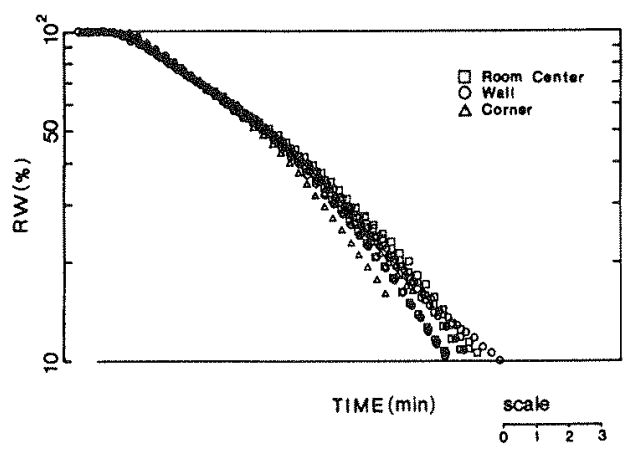

Fig. 13 Residual Weight Ratios of Wood Cribs in Semi-log

\section{DISCUSSION}

The burning rate of a fire source in a room is one of the key factors which describe the burning behavior. The radiant heat flux, the flame height, the smoke generation, etc. can be considered as a function of the mass burning rate. The engineering model of the mass burning rate for upholstered chairs proposed in Ref. [1] and Ref. [5] is given by equation (5). Then the residual weight ratio, RW, is expressed by the following equation:

$R W=m / m o=r \cdot \exp (-A(t-T p))$

Therefore, by plotting RW and t on a semi-log graph, the line of RW becomes straight 1 ine.

Fig. 11 shows the modified residual weight ratios of the burning chairs of section 2.1 in the semi-log graph. The plots of six sets of chairs are coincident and give essentially straight lines after the peak. Fig. 12 shows the modified residual weight ratios of the burning chairs of section 2.2 in the semi-log graph. Also, the plots of both type of chairs for the these plotting are coincident and, after the peak, give essentially straight lines.

Fig. 13 shows the residual weight ratios of the wood cribs in the semi-log graph, and, the plots of the residual weight ratios of wood cribs are similar for the three burning locations. And after the peak they may coincide in almost straight lines. $\mathrm{Fig} .14$ and $\mathrm{Fig.15}$ show the residual weight ratio of urethane foam in the semi-log graph. There is some scatter in the latter period, but it is possible to neglect this; the plots may give essentially straight lines. There is no obvious difference in the burning rate whether the burning location of a burning item in a room is the room center or not.

Walls and corners may have little effect unless the flames touch to the walls. In the case of chairs, it was observed that the flame of the seat back touched to the walls in the wall side and the corner tests. And in the corner test of wood cribs and urethane foams the flame touched to the walls.

When burning items are located closely along the side of a wall or in the corner of a room their burning rate must be affected somewhat by the adjacent wall. For example, the area 


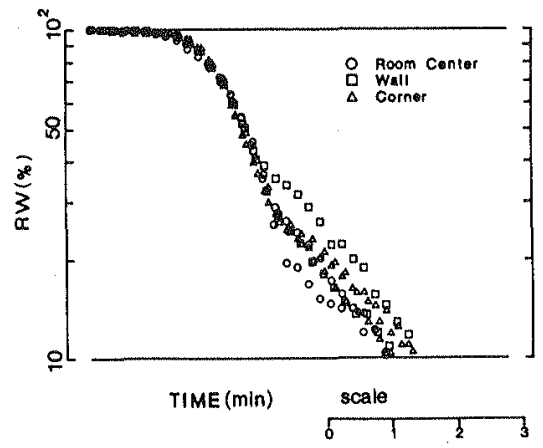

Fig. 14 Residual Weight Ratios of Urethane Foams (one s lab)

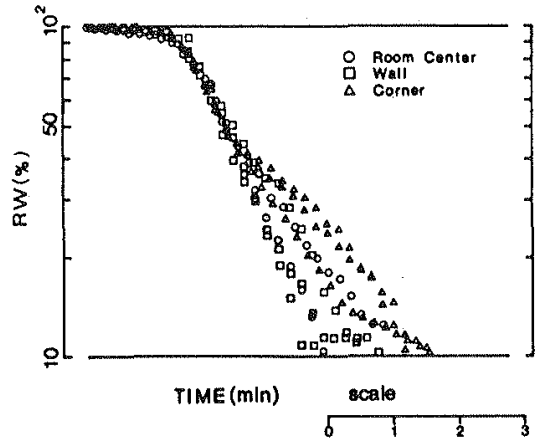

Fig. 15 Residual Weight Ratios of Urethane Foams (two slab)

for air supply to the burning region decreases, and the diffusion of the heat is disturbed by a wa11. The decomposition of charred materials may be influenced mainly by the radiation inside materials. Any way, as the burning rate ought to depend on many factors, it is not obvious how the burning rate depends on any factors.

Strictly speaking. the results of the upholstered chairs, wood cribs and urethane foams show, that the burning rate ratio in the case of the corner test may be a bit larger than in the case of the room center test, and that in the case of wall side test, it is not clear whether the burning rate ratio is larger or not. Thus, walls may have a bit effect in the case of the corner. But, from an engineering point of view, one could assume that the burning rate values of upholstered chairs are the same value whether the position of the burning item is at the center of a room, along the side of a wall, or in the corner of walls.

\section{CONCLUSION}

It was verified that the burning rate of upholstered chairs, when they burn individually in the preflashover period, is assumed to be the same value whether the position of burning item is in the center of a room or not. On the basis of the present and former[1] studies, equation (5), $\dot{m}=A \cdot r \cdot m o \cdot \exp (-A(t-T p))$, could estimate the burning rate of upholstered chairs of which burning position is in the center of a room or not.

\section{ACKNOWLEDGEMENT}

The study was basically supported by Science and Technology Agency of Japan. The author wishes to thank undergraduate students of the Science University of Tokyo for their assistance in the experiments.

\section{REFERENCES}

1. T.Mizuno and K.Kawagoe, Fire Science and Technology, Vol.4, No.1, 1984. 
2. F.Saito, "Burning Behavior of wooden materials ( in Japanese )", Research on Disaster, Vo 1.1,1980

3. J.Rockett, Fire and Materials, Vol.6, No.2, 1982

4. V.Babrauskas, NBSIR 77-1290, 1977

5. T.Mizuno and K. Kawagoe, INTERFLAM'85., Guildford, 1985

6. T.Handa and 0. Sugawa, J. of Fire and Fiammability, Vo 1.12, 1981

7. T.Handa and 0.Sugawa, J. of Fire and Flammability, Vol.13, 1982 